\title{
Variable Branching Pattern of Tibial Nerve in the Tarsal Tunnel: A Gross Anatomical Study With Clinical Implications
}

\author{
Suranjana Banik Sr. ${ }^{1}$, Leon R. Guria ${ }^{2}$ \\ 1. Anatomy, All India Institute of Medical Sciences, Bhubaneswar, IND 2. Anatomy, Regional Institute of Medical \\ Sciences, Imphal, IND
}

Corresponding author: Suranjana Banik Sr., surhrtblkr@gmail.com

\section{Abstract \\ Introduction}

Tibial nerve is a larger component of the sciatic nerve. It arises from ventral branches (Anterior Division) L4, L5, S1-S3. Then it travels along the distal border of the popliteus muscle, deep to gastrocnemius and soleus. In the leg, it is accompanied by the posterior tibial vessels and lies in the tarsal tunnel. It divides into the medial calcaneal nerve at the ankle, medial, and lateral plantar nerves under the flexor retinaculum. It carries sensory information. It can adapt to repeated forces and undergo stretch especially in ankle joint dorsiflexion and inversion of the foot. Compression of the tibial nerve in the tarsal tunnel can cause tarsal tunnel syndrome. Many surgical procedures need tibial nerve block which demands detailed knowledge of its variation.

\section{Materials and methods}

The study was cross-sectional and included lower limbs of five embalmed cadavers and 10 separate cadaveric lower limbs and was performed in the Department of Anatomy of Regional Institute of Medical Sciences, Imphal, India. The reference line $(1 \mathrm{~cm}$ width) joining two landmarks medial malleolus and medial tubercle of calcaneus called the mideo-malleolar-calcaneal axis was determined and bifurcation of the tibial nerve was classified with respect to the axis.

\section{Results}

The tibial nerve in all the cases also crossed the posterior tibial vessels. In 11 cases (55\%), the bifurcation of the tibial nerve was proximal to the mideo-malleolar-calcaneal axis with a mean distance of $1.86 \mathrm{~cm}$ above the axis, and thus comprising the maximum Type I category. Type II category, having bifurcation at the level of the axis, was found in six (30\%) cases. Type III category, having three (15\%) cases, was recorded to have bifurcation at a mean distance of $1.16 \mathrm{~cm}$.

Review began 02/24/2021 Review ended 03/04/2021 Published 03/06/2021

(c) Copyright 2021 Banik et al. This is an open access article distributed under the terms of the Creative Commons Attribution License CC-BY 4.0., which permits unrestricted use, distribution, and reproduction in any medium, provided the original author and source are credited.

\section{Conclusion}

Proper anatomical knowledge of tibial nerve branching is required to prevent surgical complications, effective nerve block, procurement of tibial nerve graft.

\section{Categories: Anesthesiology, Orthopedics, Anatomy}

Keywords: tarsal tunnel syndrome, tibial nerve, nerve block, nerve graft, nerve compression, high tibial osteotomy, electromyography, paralysis, flexor retinaculum, medial malleolar calcaneal axis

\section{Introduction}

The tibial nerve, which is the larger component of the sciatic nerve, is derived from the ventral branches (anterior divisions) of the fourth and fifth lumbar and first to third sacral ventral rami. It descends along the back of the thigh and the popliteal fossa to the distal border of the popliteus muscle. It further passes deep to gastrocnemius and soleus muscles, and then anterior to the arch of soleus muscle with the popliteal artery. In the leg, the tibial nerve travels with posterior tibial vessels and lies in a fibro-osseous tunnel called the tarsal tunnel. Medially the tunnel is bounded by the flexor retinaculum, laterally by the posterior aspect of talus and calcaneum, and anteriorly by the medial malleolus. The tibial nerve divides into medial and lateral plantar nerves under the flexor retinaculum [1].

Medial calcaneal nerve arises at the ankle, pierces the flexor retinaculum, and supplies the posterior and lower surface of the heel [2] whereas the medial and lateral plantar branches innervate the medial plantar and the lateral plantar areas of the foot, respectively, and carry sensory information from those areas [3].

The tibial nerve can undergo stretch during the movement or different positions of the lower limb, 
especially, ankle joint dorsiflexion and inversion of the foot. As a result, the nerve has to adapt itself to such changes through its mechanical properties. It can adapt to repeated forces and can slide in relation to the surrounding tissues $[4,5]$.

Compression of the tibial nerve in the tarsal tunnel due to its narrowing can cause tarsal tunnel syndrome [6]. Moreover many surgical procedures, as well as a tibial nerve block in this area, requires detailed knowledge of the variations in the level of division of the nerve.

The present study was done to analyze the topographic anatomy of the tibial nerve and its respective branches in the ankle in relation to the tarsal tunnel and its applied clinical significance.

\section{Materials And Methods}

The study was performed in the Department of Anatomy of Regional Institute of Medical Sciences on lower limbs of five embalmed cadavers and 10 separate cadaveric lower limbs that are used for undergraduate and postgraduate teaching purposes. Due to resource constraint only 20 limbs were available during the study period of one year and consecutive sampling technique was adopted. The limbs were dissected and the skin, superficial fascia was removed $30 \mathrm{~cm}$ proximal to the medial malleolus and it was continued distally to the plantar surface in each foot. Dissection was started from the popliteal fossa, continued downwards at the back of the leg until the flexor retinaculum. Each foot was placed in the anatomical position and it included the positioning of the foot $90^{\circ}$ to the tibia to standardize the measurements.

A reference line $(1 \mathrm{~cm}$ width) was determined from the two landmarks that are the tip of the medial malleolus (MM) to the medial tubercle of the calcaneus (MTC), because of their prominence and easy palpation on physical examination. This medio-malleolar-calcaneal (MMC) axis also represents the inferior edge of the flexor retinaculum and as a result, the tarsal tunnel [7]. The tarsal tunnel was defined by extending $2 \mathrm{~cm}$ proximal and distal to the axis [8]. The bifurcation of the tibial nerve was classified with respect to the defined axis. Type I represents that the bifurcation is proximal to this axis. Type II represents that the bifurcation is at the axis and type III represents that the bifurcation is distal to the axis [7].

Distances were measured using a digital Vernier caliper with $0.001 \mathrm{~mm}$ accuracy. Detailed recordings of the typical findings were recorded, and photographs of more significant anatomic dissection were captured. Mean values and standard deviation of the measurements of the right and left sides for each foot were statistically calculated. For statistical analysis, SPSS (Statistical Package for the Social Sciences) 21 version (IBM Corp., Armonk, NY) and Microsoft Excel (Microsoft ${ }^{\circledR}$ Corp., Redmond, WA) were used.

\section{Results}

In the examined 20 lower limb specimens of this study, the tibial nerve divided into the usual median and lateral plantar nerves in a tarsal tunnel in all (100\%). The tibial nerve in all the cases also crossed the posterior tibial vessels. In 11 cases (55\%), the bifurcation of the tibial nerve was proximal to the mediomalleolar-calcaneal axis with a mean distance of $1.86 \mathrm{~cm}$ above the axis (Tables 1,2), and thus comprising the maximum Type I category (Figure 1). Type II category (Figure 2) having bifurcation at the level of the axis was found in six (30\%) cases. Type III category, having three (15\%) cases, was recorded to have bifurcation at a mean distance of $1.16 \mathrm{~cm}$ distal to the axis (Figure 3). The arrangement of vessels was normal and no accessory innervations causing anomalous branching pattern was noticed. All the muscles had usual innervations.

\begin{tabular}{|c|c|c|c|c|}
\hline Types & Number of Cases $(n)=20$ & Percentage (\%) & Mean of Distance from MMC axis $(\mathrm{cm})$ & Standard deviation \\
\hline Type 1 & 11 & 55 & 1.86 & 1.46 \\
\hline Type II & 6 & 30 & At the axis & ------- \\
\hline Tyре III & 3 & 15 & 1.16 & 0.28 \\
\hline
\end{tabular}

TABLE 1: Distribution of categories of bifurcation with reference to medio-malleolar-calcaneal axis

MMC: Medio-Malleolar-Calcaneal 


\section{Cureus}

\begin{tabular}{|c|c|c|}
\hline Cadaveric Lower Limb & Right Lower Limb & Left Lower Limb \\
\hline Cadaver 1 & Type I, $1 \mathrm{~cm}$ proximal to axis & Type I, $1 \mathrm{~cm}$ proximal to axis \\
\hline Cadaver 2 & Type II, at axis & Type I, $6 \mathrm{~cm}$ proximal to axis \\
\hline Cadaver 3 & Type $1,2 \mathrm{~cm}$ proximal to axis & Type II, at axis \\
\hline Cadaver 4 & Type $\mathrm{I}, 2 \mathrm{~cm}$ proximal to axis & Type III, $1 \mathrm{~cm}$ distal to axis \\
\hline Cadaver 5 & Type II, at axis & Type I, $1.5 \mathrm{~cm}$ proximal to axis \\
\hline Individual Limbs & Right Lower Limb & Left Lower Limb \\
\hline Limb 1 & & Type III, $1.5 \mathrm{~cm}$ distal to axis \\
\hline Limb 2 & Type II, at the axis & \\
\hline Limb 3 & & Type I, $1 \mathrm{~cm}$ proximal to axis \\
\hline Limb 4 & & Type I, $2.5 \mathrm{~cm}$ proximal to axis \\
\hline Limb 5 & Type $1,1 \mathrm{~cm}$ proximal to axis & \\
\hline Limb 6 & & Type I, $1 \mathrm{~cm}$ proximal to axis \\
\hline Limb 7 & Type II, at the axis & \\
\hline Limb 8 & & Type II, at the axis \\
\hline Limb 9 & Type I, $1.5 \mathrm{~cm}$ proximal to axis & \\
\hline Limb 10 & & Type III, $1 \mathrm{~cm}$ distal to axis \\
\hline
\end{tabular}

TABLE 2: Distance of bifurcation of tibial nerve from the medio-malleolar-calcaneal axis

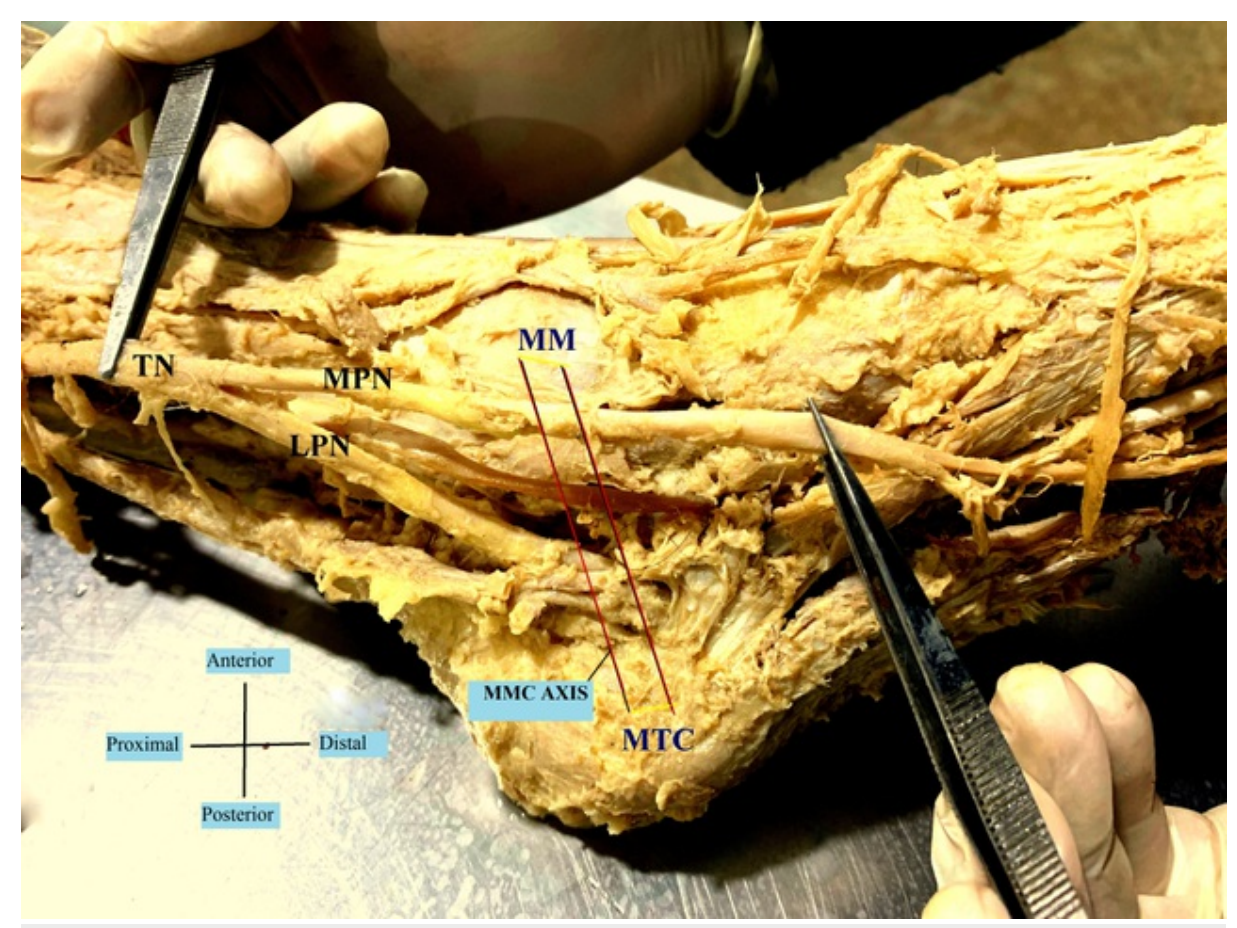

FIGURE 1: Bifurcation of the tibial nerve proximal to MMC (MedioMalleolar-Calcaneal) axis - Type I

TN- Tibial Nerve; MPN- Medial Plantar Nerve; LPN- Lateral Plantar Nerve; MM- Medial Malleolus; MTCMedial Tubercle of Calcaneus. 


\section{Cureus}

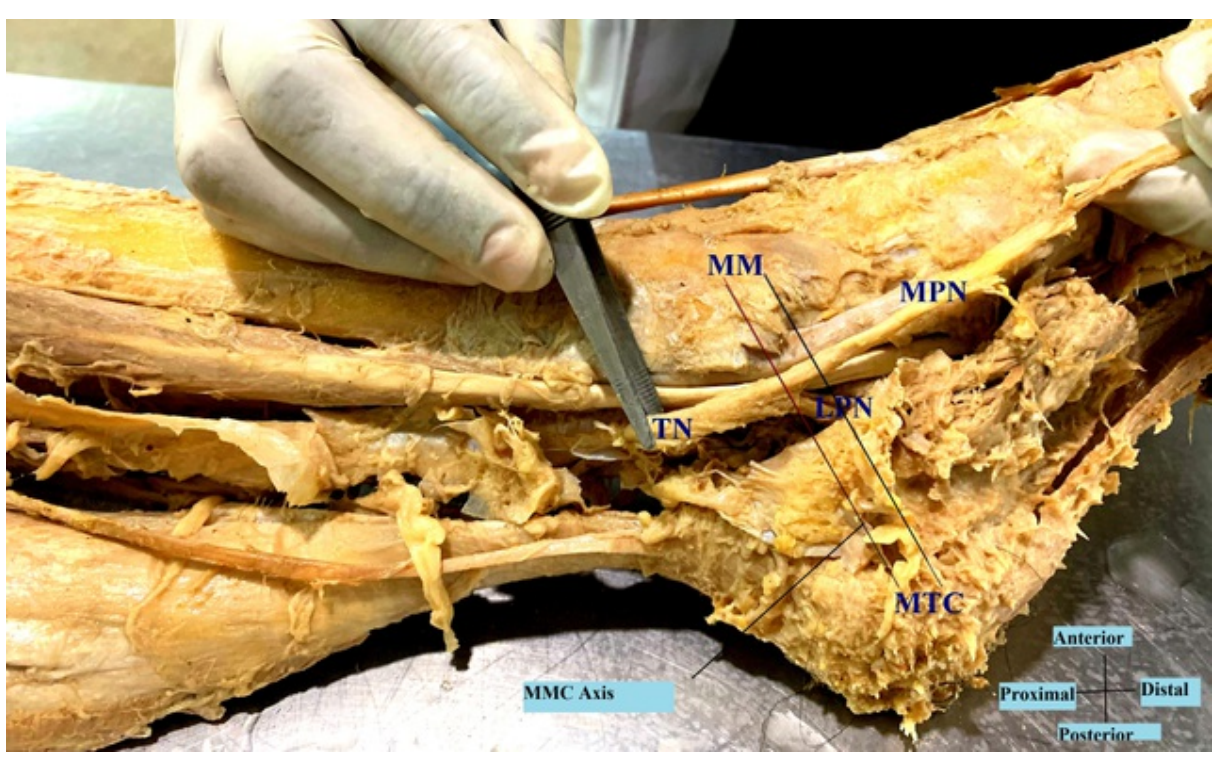

FIGURE 2: Bifurcation of the tibial nerve at the MMC (Medio-MalleolarCalcaneal) axis - Type II

TN- Tibial Nerve; MPN- Medial Plantar Nerve; LPN- Lateral Plantar Nerve; MM- Medial Malleolus; MTCMedial Tubercle of Calcaneus.

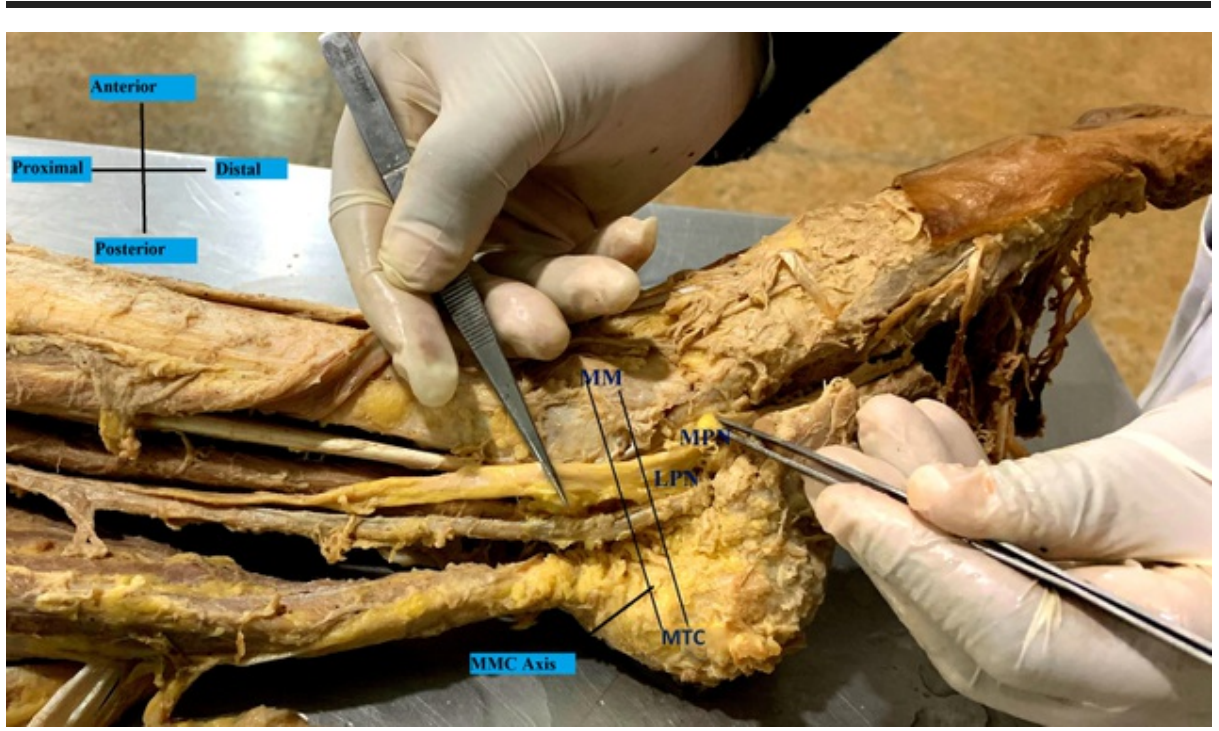

FIGURE 3: Bifurcation of the tibial nerve distal to the MMC (MedioMalleolar-Calcaneal) axis - Type III

MPN- Medial Plantar Nerve; LPN- Lateral Plantar Nerve; MM- Medial Malleolus; MTC- Medial Tubercle of Calcaneus

\section{Discussion}

The knowledge of the anatomical variation of tibial nerve bifurcation is important for the diagnosis and treatment of clinical conditions like tarsal tunnel syndrome or for surgical procedures like external nailing of tarsal bones. In a study by Andreasen Struijk et al., they found that functional electrical stimulation systems for correction of foot drop and providing standing support requires designing and implanting nerve cuff electrodes that can measure the sensory information from all the three terminal branches of the tibial nerve. They thus estimated the branching pattern, the fascicular separability, and the fascicular size of the tibial nerve posterior to the medial malleolar calcaneal axis and found high dispersion in branching pattern but mostly all (80\%) within the tarsal tunnel [3]. 
As per Louisia and Masquelet [9], and Dellon and Mackinnon [10], the bifurcation occurred in the tarsal tunnel in $73 \%$ and $95 \%$ of the cases, respectively. Ninety-three percent and $90 \%$ of the bifurcations were in the tarsal tunnel as found by Havel et al. [11] and Davis and Schon [12]. In our study, 100\% branching occurred within the tarsal tunnel.

Moreover, the branches of medial and lateral plantar nerve as well as medial calcaneal nerve, nerve to abductor digiti minimi, and motor branches to abductor hallucis and to joints, vessels and skin take origin directly from the tibial nerve. Surgeons need a thorough knowledge of the variations to avoid inadvertent cutting of nerve branches, which might be dangerous [13].

The anomalous medial plantar nerve may also lead to compression in the region of the heel causing unnecessary pain in the heel along with edema and inflammation of synovial sheaths leading to entrapment of the tibial nerve [14].

Davis and Schon have shown in their study that there is a discrepancy between the results obtained from clinical tests and electromyography studies due to anomalous branching pattern of tibial nerve above flexor retinaculum [12].

In the present study, we found that the tibial nerve bifurcated approximately $1.86 \mathrm{~cm}$ above the mideomalleolar-calcaneal axis. Now as per Burton et al. tibial nerve block was reported as a safe and effective method for controlling pain after outpatient surgery of hallux valgus [15]. A tibial nerve block is also important for postoperative analgesia after total knee arthroplasty in combination with the femoral nerve block. This block also provides good analgesia in children after knee and ankle surgery [16]. So 100\% success rate of nerve block can be guaranteed only when the higher branching knowledge, as well as average value, will be available. Knowledge of the bifurcation distance can be effectively used for planning minimal skin incisions in the case of tibial nerve decompression by the release of known anatomical compression points, the soleus arch, and the tarsal tunnel [17].

Kurtoglu et al. stated that a high division of the tibial nerve was associated with an accessory flexor digitorum muscle [18]. We did not come across such findings but probably a larger sample size can help in better evaluation of this. The tibial nerve is often iatrogenically injured during fibular graft harvest, high tibial osteotomy, and fascial release procedures [4]. The topographical knowledge will also help to procure the allogenic vascularised tibial nerve graft after limb salvage along with nerve bank storages for future use [19].

This is the first study of this kind in the North-East Indian population. The major limitation of the study is the small sample size due to resource constraint. The study can be replicated in different ethnic group and with a larger sample size to estimate statistical significant difference in variations.

\section{Conclusions}

The tibial nerve is involved in many clinical conditions starting from poliomyelitis, nerve compression syndromes, tuberculosis, leprosy, idiopathic heterotopic ossification. Damage to either of the branches can cause paralysis of the three muscles supplied by it. So anatomical knowledge of the motor branching will help to reduce surgical complications involving this region. It will also help to reduce the discrepancies in clinical and electromyographical correlation studies. Effective nerve blocks will be hastened. Nerve grafts can be used effectively for nervous tissue banks and limb salvage surgeries can be hassle-free and successful.

\section{Additional Information}

\section{Disclosures}

Human subjects: Consent was obtained or waived by all participants in this study. Research Ethics Board of RIMS Imphal issued approval Not applicable. There was no issue with regards to ethical permission and it was granted since the cadavers and individual limbs that have been studied are already made available after proper documentation for the educational purpose and the teaching curriculum in the college. The cadavers were used for undergraduate anatomy teaching and we studied a part of them. Animal subjects: All authors have confirmed that this study did not involve animal subjects or tissue. Conflicts of interest: In compliance with the ICMJE uniform disclosure form, all authors declare the following: Payment/services info: All authors have declared that no financial support was received from any organization for the submitted work. Financial relationships: All authors have declared that they have no financial relationships at present or within the previous three years with any organizations that might have an interest in the submitted work. Other relationships: All authors have declared that there are no other relationships or activities that could appear to have influenced the submitted work.

\section{Acknowledgements}

My heartfelt gratitude towards those who have donated their bodies for the advancement of medical education and research. Also, I want to thank the Department of Anatomy, RIMS, Imphal for their 


\section{References}

1. Gray H, Williams PL, Bannister LH: Nervous system. Grey's Anatomy, 38th Ed.. Berry MM (ed): Churchill Livingstone, New York; 1996. 1284-1286.

2. Malar D: A study of tibial nerve bifurcation and branching pattern of calcaneal nerve in the tarsal tunnel . Int J Anat Res. 2016, 4:2034-2036.

3. Andreasen Struijk LN, Birn H, Teglbjærg PS, Haase J, Struijk JJ: Size and separability of the calcaneal and the medial and lateral plantar nerves in the distal tibial nerve. Anat Sci Int. 2010, 85:13-22. 10.1007/s12565009-0045-y

4. Apaydin N, Loukas M, Kendir S, Tubbs RS, Jordan R, Tekdemir I, Elhan A: The precise localization of distal motor branches of the tibial nerve in the deep posterior compartment of the leg. Surg Radiol Anat. 2008, 30:291-295. 10.1007/s00276-008-0321-X

5. Shacklock M: Clinical Neurodynamics: A New System of Musculoskeletal Treatment. Elsevier, Edinburgh; 2005.

6. Sammarco GJ, Conti SF: Anomalous tibial nerve. A case report . Clin Orthop Relat Res. 1994, 239-241.

7. Bilge O, Ozer MA, Govsa F: Neurovascular branching in the tarsal tunnel. Neuroanatomy. 2003, 2:39-41.

8. Torres AL, Ferreira MC: Study of the anatomy of the tibial nerve and its branches in the distal medial leg . Acta Ortop Bras. 2012, 20:157-164. 10.1590/S1413-78522012000300005

9. Louisia S, Masquelet AC: The medial and inferior calcaneal nerves: an anatomic study . Surg Radiol Anat. 1999, 21:169-173. 10.1007/BF01630895

10. Dellon AL, Mackinnon SE: Tibial nerve branching in the tarsal tunnel. Arch Neurol. 1984, 41:645-646. 10.1001/archneur.1984.04210080053013

11. Havel PE, Ebraheim NA, Clark SE, Jackson WT, DiDio L: Tibial nerve branching in the tarsal tunnel. Foot Ankle Int. 1988, 9:117-119. 10.1177/107110078800900304

12. Davis TJ, Schon LC: Branches of the tibial nerve: anatomic variation . Foot Ankle Int. 1995, 16:21-29. $10.1177 / 107110079501600105$

13. Sharma S, Wadhwa A, Bhardwaj S: A study on the level of termination of tibial nerve: review of literature and its clinical implications. Int J Anat Res. 2016, 4:1901-1900. 10.16965/ijar.2016.109

14. Moore KL, Dalley AF, Agur AMR: Clinically Oriented Anatomy, 6th Ed.. Wolters Kluwer and Lippincott Williams and Wilkins, Baltimore; 2010.

15. Burton C, Sajja A, Latthe PM: Effectiveness of percutaneous posterior tibial nerve stimulation for overactive bladder: a systematic review and meta-analysis. Neurourol Urodyn. 2012, 31:1206-1216. 10.1002/nau.22251

16. Tobias JD, Mencio GA: Popliteal fossa block for postoperative analgesia after foot surgery in infants and children. J Pediatr Orthop. 1999, 19:511-514.

17. Martín MA, Ollé G, Pellejero JA, Torruella R, Yuste M, Pou N: Comparison of the post-surgical analgesic effectiveness of tibial (at internal malleolus level) and common peroneal nerve block with infiltration of the surgical wound in Outpatient Surgery of the hallux valgus. (Article in Spanish). Rev Esp Anestesiol Reanim. 2012, 59:197-203. 10.1016/j.redar.2012.02.008

18. Kurtoglu Z, Uluutku MH, Can MA, Onderoglu S: An accessory flexor digitorum longus muscle with high division of the tibial nerve. Surg Radiol Anat. 2001, 23:61-63. 10.1007/s00276-001-0061-7

19. Elbarrany WG, Altaf FM: The tibial nerve and its vasculature: an anatomical evaluation . Int J Morphol. 2017, 35:812-819. 